\title{
Why Sanitation Program is too slow in middle east states of India? Problems and Solutions
}

\author{
Dr. Mridula Sharma \\ J.S.H Mahavidyalaya, Amroha (J.P. Nagar) U.P. India 244221
}

\begin{abstract}
ABSTRUCT:- The rural sanitation program in India was introduced in the year 1954 as a part of the first five year plan of the Government of India. The 1981 Census revealed rural sanitation coverage wan only $1 \%$.so from the starting there are so many program have been driven by Indian Government and Big industrial lobbies, but now in 2017 rural India is still suffering from bad sanitation problem. According to the MoDWS the over all sanitation coverage of India in year 2016-17 is $63.74 \%$ and this percentage comparatively other neighbor countries like Pakistan, Bangladesh is very low. In India some states are doing well in Swachh Bharat Mission like Sikkim, Uttarakhand, Kerala, Himachal Pradesh etc. In this research paper we will discuss about the rural areas of Middle East States The most backward and ancient part of India, here we analysis the reason of slow development, if we go through the window of our history we will see that the people of this area were more developed and self dependent before British era, so we will take a sharp glance on their lives. Madhya Pradesh, Chhattisgarh, Jharkhand, Odessa, W Bengal ,Tamil Nadu, Bihar are the poor states of India., and here the sanitation rate is below $70 \%$ and in few states it is below $40 \%$.So in this research we will discuss the reason and their solutions that why sanitation program is too slow?
\end{abstract}

KEY WORDS: Water and Sanitation, CLTS, Local partner organizations, Impact assessment.

\section{INTRODUCTION:}

In India Open Defecation is Mental Disease and the the symptoms of this disease are Alternative Approaches to Sanitation : A Paradigm Shift. There is no point here that we have toilets or not, there is a matter of open defecation free country. In many villages people have luxurious toilets but they don want to use them and the reason is very simple "we don't feel comfortable in between four walls" and some places villagers told us that," Shauchalay to keval mahilao ke liye h" What a pathetic dialogue is this.So, in some states the reason of open defecation is not poverty and illiteracy people don't want to leave this habit That's why they need BCC(Behavior Change Communication). Some states like Madhya Pradesh, Bihar, Jharkhand, Odessa, Tamil Nadu, W. Bengal are suffering by different aspect and problems. These states are basically rural states, and agriculture is their main occupation. They are living here from the ancient era, that time they were king of agriculture land, they had not need to buy anything they were skilful tribes. During the British era they had ruined their all. They were exploited and tortured by main stream people now they have lost their all skills and they are living like slaves. Government is trying to drag them in main stream for that they are applying so many skims and policies but what is the result rural areas are still backward. Odessa (39.73\%), $\operatorname{Bihar}(27.47 \%)$,Jharkhand(50.81\%), these states are

TABLE NO- 1

\begin{tabular}{|l|l|}
\hline States & Sanitation Coverage in percentage (\%) \\
\hline W. Bengal & 88.23 \\
\hline Chhattisgarh & 76.17 \\
\hline Tamil Nadu & 68.12 \\
\hline Madhya Pradesh & 55.91 \\
\hline Jharkhand & 50.81 \\
\hline Odessa & 39.73 \\
\hline Bihar & 27.47 \\
\hline
\end{tabular}

Suffering from worst condition social and economic condition is in very bad condition. Open defecation and lack of sanitation and hygiene in general is an important factor in causing various diseases, most notably diarrhea and intestinal worm infection but also typhoid, cholera, hepatitis, polio, trachoma, and others. In these states, lots of sanitation programs are activating but after that we are far away from success, but from last three years these programs are running rapidly. 
Middle East States are suffering from bad sanitation and Government policies are too slow here, actually problem is awareness, these people are much far from modern facilities and resources, one more problem is in Jharkhand and Chhattisgarh and Odessa Naxal problem officials has been terrorized by them . Government is running demand driven vocational training courses comprising long Term training and Short Term training and Instructor Training courses. Funds allocated to Bihar and Jharkhand are Rs.41.669 crore and Rs 69.48 crores respectively. Officials has been trained by best psychologist and trainers. They learn there about Behavior Change approach to deal with those people.

Conditions are not good there and full of difficulties but we should have to understand their problems and situations, comparatively rural areas urban areas are doing much better according to the recent survey Indore is the first cleanest city and Bhopal is second, so rural areas of these states are fighting with their circumstances. Social atmosphere is also very sick in rural areas in these states. Water supply and poor personal hygiene. In states like Bihar, Jharkhand and Madhya Pradesh where the levels of sanitation is poorest has highest number of child malnutrition in the country. Moreover, health services are given low priority in these states. Young girls in the rural area and the slums lack proper knowledge about menstrual sanitation .According to the reports, $88 \%$ of these girls don't have access to water, sanitation and hygiene, including soap or sanitary supplies. Out of the total female population in these states, shockingly only about $12 \%$ have access to proper sanitary napkins. Open defecation gave birth to many water born disease, Malnutrition and stunted growth in children. In many cases the child even loses his life. Open Defecation is a curse for all livings, in these states situation is not like this from starting it has been created by slavery by British rule, and now we need to change the mind set that Open Defecation is the main producer of diseases.

\section{STUDY AREA:}

Middle East area of our country has a very old geographic structure and culture also, most of the Old Indian Tribes are living here, some states are new developed like Chhattisgarh and Jharkhand. Whole Geographical area is made by hard rocks and plateaus and thorny bushes and dense forest comparatively this area is very much complicated than northern states people cannot make their infrastructures easily.All these Middle east states have mostly tribal population. Due to the different linguistic, cultural and geographical environment and its peculiar complications, the diverse tribal world of this area has been largely cut off from the mainstream of development. Total sanitation programmes are slow in middle east states of India. There are so many reasons to explain this blunt truth is this that in this area of our country all sanitation programmes which are conducting by governal and non governal agencies are too slow actually not programmes, the result of these programmes also.From the year 1986 so many programmes from local and foreign sources are conducting in this area. India has spent over $\$ 3$ billion on constructing toilets across the country since 1986, but the condition is still same. Middle East states are on the last in sanitation surveys. We accept it that from the last two or three years the condition is becoming better. But still results are too slow so we will discuss on root problems and solutions

\section{METHODOLOGY:}

The present research paper is certainly based on desk study, involving compilation analyses of information and data from official websites, papers, media reports and articles. This research analysis that why Middle East States of our country are too slow in sanitation field? Why sanitation programmes are too slow here? Our government applying lot of policies and plans to improve the condition than why this area is stand on last position. By the help of data and analysis we will present the problems and their solutions to face the conditions. Total Sanitation problem in Middle East States is so big in present research paper we will study on root problems and would come to know about cultural, environmental, economic reason of failure, with the help of population study, society management, distribution, standard of society, literacy rate.

\section{RESULT AND DISCUSSION:}

Middle East States means W. Bengal, Jharkhand, Chhattisgarh, Orissa, Madhya Pradesh, Tamilnadu, Bihar these states have income below the national average, with Bihar having the lowest income per capita. We are not justifying that poverty can allow to do open defecation but it is one of the reasons. There are so many facts and things to research. Open defecation is not a cause it's a habit for people and habits can change weather it is from long time. Middle East states are worst effected states as far as malnutrition is concerned. The issue of lack of sanitation (open defecation) is linked to human health, dignity and safety of women and children. People across rural areas in Middle East States predominantly practice open defecation due to traditionally accepted behavior.Government and several voluntary organizations have implemented many interventions bringing huge resources to the issue of sanitation, but the impact on ground has been slow. Jharkhand, Chhattisgarh, Bihar, Tamil Nadu, Madhya Pradesh, Odessa, West Bengal are bottom states score on the bottom side. 
One of the major reasons for this has been the lack of acknowledgement, involvement and demand from communities themselves for sanitation service. People are unknown about the harmful results of bad sanitation (open defecation). Organizations are providing them knowledge and awareness from the method of CLTS and Behavior Change.

Standard of Living:

To understand the problem of bad sanitation in Middle East States. We should know about the living style and about the population of this area. It is very easy to criticize but for change we should know about those peoples who are living their in a very difficult situation. The central India tribal belt stretches from west up to east across the state of Madhya Pradesh, Chhattisgarh, Jharkhand, Odessa, Tamil Nadu, and W. Bengal. It is among the poorest region of the country. Over $90 \%$ of the Belt's tribal population is rural with primitive agriculture. According to the Table no.1- Density of population compare of whole country is so mismatch. According to this table we can understand that Bihar and W. Bengal has dense population. Basically this is a populated area and mostly peoples are uneducated, homeless and economically backward.

Table 2: Population Share and Population Density by Middle East States- 2011

\begin{tabular}{|l|l|l|}
\hline STATES & $\begin{array}{l}\% \text { of TOTAL NATIONAL } \\
\text { POPULATION }\end{array}$ & DENSITY of POPULATION \\
\hline Bihar & 8.07 & 880 \\
\hline Chhattisgarh & 2.02 & 154 \\
\hline Jharkhand & 2.62 & 338 \\
\hline Madhya Pradesh & 5.88 & 196 \\
\hline Odisha & 3.57 & 236 \\
\hline Tamilnadu & 6.05 & 478 \\
\hline W. Bengal & 7.81 & 904 \\
\hline
\end{tabular}

Source: Census of India 2011

If we analyses the physical situation of this area we would found that most of the part of this area is covered by bushy dense forest, river valleys, plateau, hard rocks, tough to break. A major part of population is tribal who lives cultural rural lives.A tribe is a group of people, usually staying in jungle areas, in a small locality, absolutely illiterate poor, hardly clad in clothes, usually dark and frail, fully living within their own community whose marriage always takes place among themselves, engaged in hunting and searching for roots , shoots and fruits as their veg food and roasted animal as non veg food, completely oblivious of the country's political and economic condition, resisting all efforts of development and have a strong dislike for strangers and modern educated community.

HISTORY: A tribal society is a primitive society which lived in early period of human history but can be found in large number of groups in all countries including India. There has not been any change of tribes in their belief, life style and religion which prevent them from mixing with any outsider or educate community whom they greatly dislike.We can see in Table no. 2- that tribal population basically lives in rural areas these rural areas are covered by dense forests and rocky mountains and valleys. Tribal life in central East India is an excellent instance of the blending of rural and urbanity. Most of the Tribal communities are still living in deep forests and avoid mixing with outsides in order to protect their own unique culture. We are not justifying that Due to their backward condition they are defecating in open areas. This is not their culture and history, Tribal communities in history were very much self dependent they can survive without buying anything. But from the passing few decades They have faced so many worst situation like exploitation and slavery. According to Table No. 2 there is a big difference between rural and urban population so we'll have to more work in rural areas.

Table 3: Total Tribal Population in Middle East States

\begin{tabular}{|l|l|l|l|}
\hline STATES & TOTAL & RURAL & URBAN \\
\hline Bihar & $1,336,573$ & $1,270,851$ & 65,722 \\
\hline W. Bengal & $5,296,953$ & $4,855,115$ & 441,838 \\
\hline Jharkhand & $8,645,042$ & $7,868,130$ & 776,892 \\
\hline Odisha & $9,590,756$ & $8,994,967$ & 595,789 \\
\hline Chhattisgarh & $7,822,902$ & $7,231,082$ & 591,820 \\
\hline Tamil Nadu & 794,697 & 660,280 & 134,417 \\
\hline Madhya Pradesh & $15,316,784$ & $14,276,874$ & $1,039,910$ \\
\hline
\end{tabular}

Sources: Census of India 2011

Economic Condition:

There are rich nations as well as poor nations in the world. Some nations may be more developed or less developed, or the developing ones. Their rates of development are different. The conditions in which they developed themselves are different. The type planning they adopt for developing themselves varies from one nation to another The technique of planning preferred are also different. Like India has poverty as a national problem but some states are poorer than others. Some states are more developed than others. 
Backwardness, with or without the prefix economy, is generally employed as synonymous with poverty in growth economics. By and large, a poor state is a backward state. Its development is low. We use per capita income of a state to rank it along with other states and infer that a state which has a lower per capita income then another state is poorer or more backward, by comparison. This is a list of seven Middle East States of India ranked according to poverty as on 16 September 2013. The list is compelled from the annual report of Reserve Bank of India .The rank is calculated according to the percentage of people below poverty line and is based on MRP consumption.

TABLE NO.4- State wise percentage of people below poverty line

\begin{tabular}{|l|l|}
\hline STATE & Poverty(\% of people below poverty line) \\
\hline Tamilnadu & 11.28 \\
\hline W. Bengal & 19.98 \\
\hline $\begin{array}{l}\text { Madhya } \\
\text { Pradesh }\end{array}$ & 31.65 \\
\hline Odessa & 32.59 \\
\hline Bihar & 32.6 \\
\hline Jharkhand & 36.96 \\
\hline Chhattisgarh & 39.93 \\
\hline
\end{tabular}

Sources: Reserve Bank of India, Government of India. 2013. Retrieved April 20, 2014.

According to the Table No. 3 Chhattisgarh is on last position in India. About one third of Chhattisgarh's population lies below over extreme poverty line 93\% people are poor in Chhattisgarh. Jharkhand is on second rank from the below side of ladder. Poverty at the state level is around at $36.96 \%$. Jharkhand's social indicators such as literacy, enrollment. Infant mortality and child nutrition are below all India average Bihar is on Third rank in the list of poor states in India. Half the population Bihar is below poverty line. Poverty is around $35.75 \%$. The reason for the backwardness of agriculture are both institutional and technological. And structural and institutional factors acted as a barrier agrarian transformation. Next is Odessa, Odessa has the second highest proportion of scheduled caste and tribal people in India Half of the people in Odessa are educationally backward and rural female literacy, lower than the national average. Odessa has the highest percentage of children aged between six and fourteen years who are out of school. Madhya Pradesh is the home to the largest number of schedule tribes (STs) in India and is often called the tribal state of India. The rural poor in forested area, particularly tribal populations are dependent on the forest resources for subsistence income and employment.

Status of Human ResourceAny program cannot work without participation of population as human resource, so human resource participation is very necessary to success every program. Water and sanitation program is fully based on "Let people realize for themselves" \& "Unites the community". So the success of this programme is depend on the right utilization of human resource. These seven states are most populated areas of country we only need a good management of human resource development we need some essential factors likeEducation, health and nutritional status of the people, and their specialized training determine the quality of population as a human resource. For the implementation of any program we will have to involve community, if the entire community is not involved, open defecation by a few people places the entire habitation at risk. This is happening in most villages of India where toilets have been built but not put to use. Favorable public health outcomes are secured only when the entire community changes its behavior.The Swachh Bharat Mission's baseline survey report of 2012 named Odisha and Bihar as the states having the worst sanitation figures in the entire nation. While $88 \%$ of households in Odisha had no toilets, the figure stood at $78 \%$ for the state of Bihar. While both state have enough human resource but, useless because, if resource would never b utilized they will be paralyzed. So for the success of this programme we will have to use this resource. This whole approach is called CLTS, a reinvented approach is required to eliminate open defecation under overarching Swachh Bharat framework and the current scenario in Bihar presents a compelling case for large scale community engagement.Human resource is the most powerful tool in sanitation program, so we have to use it in proper way. All these seven states are mostly populated by tribal's communities and they are continuously exploiting by money minders. Policies and subsidies are not enough for them but also proper education and awareness is also very essential so that they can judge that what is good or bad for them.

\section{PROBLEMS:}

Sanitation Or any other welfare programs are only can success with the proper contribution from root. If we are aware with the bad and good result of any step of our, we will be conscious ,so first of all we will have to be Educated, aware with the result of any bad habit. Poverty and Illiteracy is the main root cause of failure of any welfare program. Both of this cause is only applicable on the rural area of all those seven states. 
POVERTY: As we can see in the map of India the darkest area of our country is below poverty line. So poverty is one of the main causes of failure of sanitation program in these seven states. Since there are so many people working in agriculture and living in rural areas, the agriculture sector has an unrivaled priority in policies aimed at reducing poverty. And because there is a simple and straightforward link between rural poverty and agriculture productivity. The number of poor in India is measured by a poverty line that is probably one of the most disputed and incessantly attacked tool in the world of development economics. What's more the "World Bank's Controversial Poverty line has its origins in the Indian model! It is simply what some call a "starvation Line", a line that accounts for the feeling of satiety: measured in calories. $70 \%$ part of population here don't have access to decent toilets , 35\% of households don't have a nearby water source. There's also the problem of huge segments of the population that are

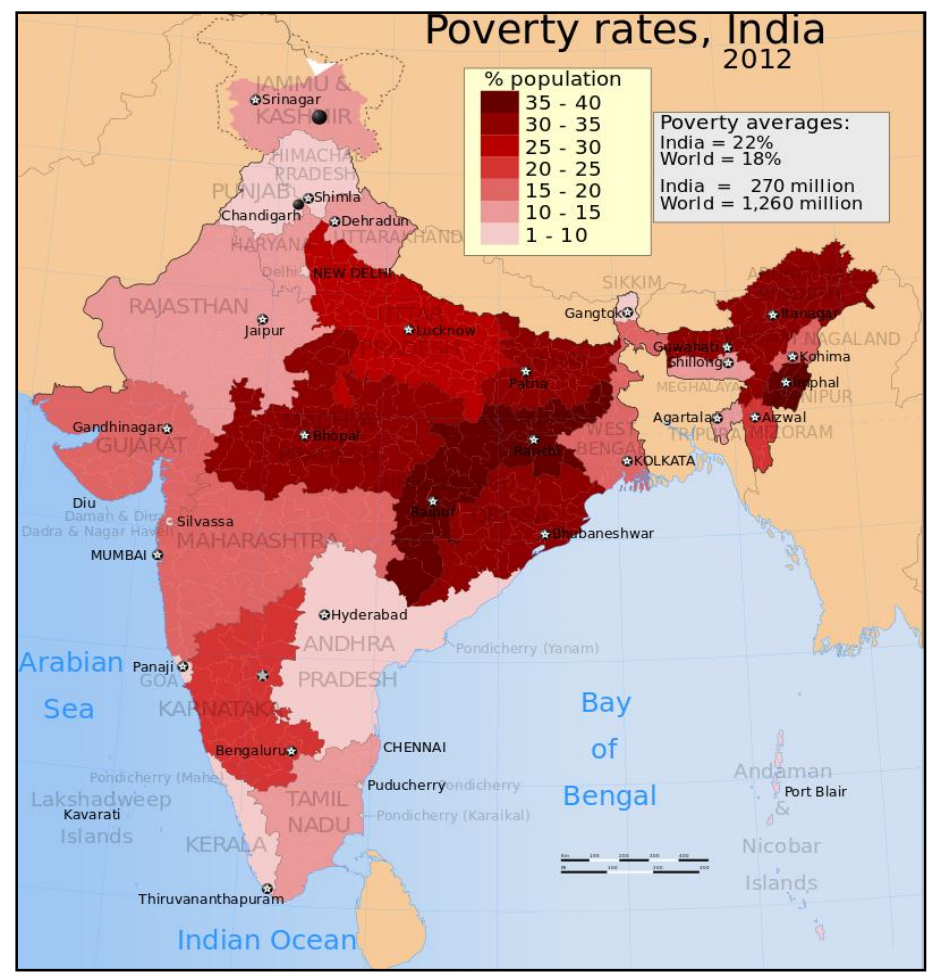

not included in the official poverty count, namely the Dalits, Women and minority ethnic tribes. Poverty is not only the reason of failure but it is one of the reasons, Due to poverty in their whole life they only think about enough food and shelter only, not for any other thing. ILLITERACY: To know the development in a society, Literacy is another proper indicator of development. Literacy plays a major role in the development of a nation. According to the table no 4 Bihar with a figure of $63.82 \%$ has the lowest literacy rate in India . Government of India has taken several measures to improve the literacy rate in villages and towns of India, "Our Constitution fathers did not intend that we just set up hovels, put students there, give untrained teachers, give them bad textbooks, no playgrounds, and say, we have complied with Article 45 and primary education is expanding... They meant that real education should be given to our children between the ages of 6 and 14 ." $-\mathrm{M}$. C. Chagla - Education Minister of India, 1963-66. In the Middle East States more than 40 percent of the girl student drop out even before completing the primary level education. We found that the fear of sexual assault, the need for privacy, and the generally unusable state of sanitation facilities results in girls controlling their bladders for as long as 13 hours a day. Girls in this area tend to miss school an average of three to six days a month due to the inability

TABLE: 5- Ranking of States By Literacy Rate

\begin{tabular}{|l|l|l|l|l|}
\hline Rank & STATES & $\begin{array}{l}\text { Literacy } \\
\text { Rate(\%)-2011 } \\
\text { Census }\end{array}$ & $\begin{array}{l}\text { Male Literacy } \\
\text { Rate(\%)-2011 } \\
\text { Census }\end{array}$ & $\begin{array}{l}\text { Female } \\
\text { Literacy } \\
\text { Rate(\%)-2011 } \\
\text { Census }\end{array}$ \\
\hline 1 & Tamil Nadu & 80.33 & 86.81 & 73.86 \\
\hline 2 & W Bengal & 77.08 & 82.67 & 71.16 \\
\hline 3 & Odessa & 73.45 & 82.40 & 64.36 \\
\hline 4 & Chhattisgarh & 71.04 & 81.45 & 60.59 \\
\hline 5 & Madhya Pradesh & 70.63 & 80.53 & 60.02 \\
\hline
\end{tabular}




\begin{tabular}{|l|l|l|l|l|}
\hline 6 & Jharkhand & 67.63 & 78.45 & 56.21 \\
\hline 7 & Bihar & 63.82 & 73.39 & 53.33 \\
\cline { 1 - 4 }
\end{tabular}

SOURCE: Government of India

To effectively manage their menstrual health at school. This eventually contributes to almost $23 \%$ of girls dropping out of school on reaching puberty a, in turn, critically undermines their potential as individuals and future workers. So, the cycle continues like this, if parents are not educated than how can they educate their wards.

\section{SOLUTIONS:}

To solve the problem of sanitation, we will have to work together selflessly. In those seven states all sanitation or welfare programs are slow because lake of determination. Children are suffering from malnutrition, women are suffering from several reproductive and sexual problems death rate is increasing and health rate is also going to the low, and we the solution of these problems. Government and private Organizations will have to work together and they are working. Government officials and Self motivators should collaborate with each other to give rapid speed of this program in poor states. To prevent the all diseases people should only do the some small things like washing hands, stop defecate in open. If only these things will apply nobody can failure the sanitation programs. Government-built latrines will not end open defecation for decades yet. We should understand the needs instead of lectures, speeches, people who are living in rural areas in these seven states, they have not enough food, not proper shelter and not even good education or awareness. How can they think about sanitation and all. They have no need of government subsidy or government built toilets they only need awareness about cheap toilets which can be used in small quantity of water.

\section{CONCLUSION:}

For the success of Total Sanitation Program in the rural areas of these seven states, Government, officials and NGOs have to work together and specially we would have to forget about the subsidy. Now this program is running with the help of Behavior Change approach and this trick is doing work, actually. Middle East States are developing states, Government should apply some reliable policies to give support of tribes. They have need to support in education and employment areas. Every place has some distinct quality and their people also has lots of skills, so government should encourage them to develop their skills so that they could b developed in future.

\section{REFRENCE:}

[1] www.healthissuesindia.com/poor sanitation

[2] www.thehindubussinessline.com

[3] www.chiristiantoday.co.in

[4] Government of W. Bengal, economic review,2007-8.

[5] www.downtoearth.org.in/

[6] Sbm.gov.in/

[7] www.deccanherald.com

[8] Ministry of Drinking Water and Sanitation.

[9] Government of India - Literacy Data. :

[10] Reserve Bank of India, Government of India. 2013. Retrieved April 20, 2014.

[11] Census of India 2011 